\title{
SHIFTING AIRCRAFT FROM UNCOMMON TO COMMON
}

\author{
Puti Allia Rahmadhani ${ }^{1}$, Garnis Nidyaningsih ${ }^{2}$, Aditya Wardana ${ }^{3}$, \\ Nursery Nasution ${ }^{4}$ \\ 1. STMT Trisakti, 2. STMT Trisakti, 3. STMT Trisakti, 4. Malaysia \\ Institute for Supply Chain Innovation \\ corresponding author: rahmadhani030296@gmail.com
}

\begin{abstract}
Aircraft maintenance facility is the second contributor of all operating cost in the airlines. In fact, the cost of maintenance facility continuously increases in the last five years. Therefore, airline business has to reduce their operating cost, especially for direct maintenance cost. Maintenance cost is defined by the type of maintenance implemented in the aircraft, other than that fleet commonality concept also affects the level of maintenance. In general, type of the maintenance is divided into two categories; preventive maintenance and corrective maintenance. Between these two categories, corrective maintenance is the one which contribute high cost for direct maintenance cost of the aircraft. Reducing the maintenance cost is a pivotal thing to improve economy of the airlines company. This paper explains how fleet commonality influence direct maintenance cost in airlines business using descriptive method.
\end{abstract}

Keywords: commonality, direct maintenance cost, aircraft, airlines economic, maintenance facility

\section{Introduction}

Unquestionably, there are many airlines in this world and the competition is getting severe. The airline industry market is growing steadily. Jani Kilpi had a survey that shown from time to time, the number of airline businesses has increased from 180 to 800 (Jani Kilpi, 2007). Airline industry is having more unstable economic fluctuation than other industries. To survive in this industry, airlines must have competitive advantage which means minimizing the cost. The existing of low cost carrier makes the full service airline has to work harder to attract customer retention of the full service airlines because low cost carrier is already one step forward for its strategy in lowering their ticket price regarding to the lower operating cost that should spent by low cost carrier (Simarmata, Suryana, Kaltum, \& Oesman, 2016). 
In airline industry, we already understand that there are several significant costs that an airline should expend to continue its operation. The costs are divided into several categories, which are:

Table 1.

AIRLINES OPERATING COST

\begin{tabular}{|c|c|c|c|}
\hline $\mathrm{NO}$ & $\begin{array}{c}\text { COST } \\
\text { CATEGORIES }\end{array}$ & COST DESCRIPTION & REMARKS \\
\hline \multirow[t]{2}{*}{1} & \multirow{2}{*}{$\begin{array}{c}\text { Direct Operating } \\
\text { Cost }\end{array}$} & $\begin{array}{c}\text { Fuel, Maintenance, Ground } \\
\text { Handling, Route Charge, Flight } \\
\text { Hour Crew, Catering, Airport } \\
\text { Lounge, Landing Fee, } \\
\text { Reservation }\end{array}$ & Variable Cost \\
\hline & & $\begin{array}{c}\text { Aircraft Rent, Aircraft } \\
\text { Insurance, Loan Interest, Crew } \\
\text { Salary, Mechanic Salary, } \\
\text { Training }\end{array}$ & Fixed Cost \\
\hline 3 & $\begin{array}{c}\text { Indirect Operating } \\
\text { Cost }\end{array}$ & $\begin{array}{l}\text { Station and Ground Cost, Pax } \\
\text { Service and Insurance, } \\
\text { Ticketing Sales and Promotion, } \\
\text { Depreciation Cost, Overhead } \\
\text { and Administration Cost, } \\
\text { Salaries Back Office }\end{array}$ & \\
\hline
\end{tabular}

From cost categories above, airline companies usually have to spend more budgets on fuel, and then the second biggest budgets are for maintenance cost. Normally, aircraft maintenance cost is not the biggest operating cost, but it is the biggest manageable cost in the airline industry if properly scheduled, even though there is still a delay and unexpected corrective maintenance that cannot be predicted and controlled. In Heisey's opinion, maintenance cost for airlines is usually taking around 10-20 percent part of aircraft operating cost (Heisey, 2002).

Aircraft maintenance is an activity that can restore an item of the aircraft, whether it is consumable or routable parts to be a durable condition and the activities consist of giving service, repairing, modifying, overhauling, inspecting and determining the condition of the aircraft. There are two types of maintenance, preventive maintenance and corrective maintenance, where preventive maintenance is known as scheduled 
maintenance and corrective maintenance is known as unscheduled maintenance.

In maintenance cost, there is Direct Maintenance Cost (DMC) which explains more detail about any cost which involved directly expended to do maintenance of an aircraft. Based on IATA analysis about Airline Maintenance Cost Executive Commentary, it is already explained specifically that direct maintenance costs consists of Direct Maintenance Cost by segment and Direct Maintenance Cost by element (IATA, 2011).

Direct Maintenance Cost by segment determined by engine maintenance, line maintenance, base maintenance, and component maintenance. For executing these four maintenances, there will be Direct Maintenance Cost by elements which are the people who will do these four maintenances. Direct Maintenance Cost by element consists of labor, outsourced, and material. Labor plays a significant role in the financial equation of airlines, although some maintenance cannot be done by labor. They should be done by third-party outside the manufacturer and the operator. The airlines have to spend extra cost for hiring outsources services. To prevent unexpected incidents, both airlines and outsource services should sign employment contract which will be a win-win solution for both of them.

The most important element for the airlines to build an airline company is fleet. Fleet can be described as how many collections of aircraft that airline had (Jani Kilpi, 2007). Those airline companies will order many types of aircraft from aircraft manufacturers that already exist in the world, such as Airbus, Boeing, Bombardier, Embraer, Tupolev, etc. Many airlines order many types of aircraft in order to fulfill the routes they provide for their passengers. There are many reasons why airlines order different type of aircraft with different size. One of the reasons is to suit the route length variation.

Besides those who order different type of aircraft, there are few airlines who only order one type of aircraft. It is usually called fleet commonality concept. Fleet commonality consists of one-single type of 
aircraft or known as fleet families (Brüggen \& Klose, 2010). It plays a significant role in the airline industry. It cannot be denied that all airlines should implement this commonality concept, even though it is very difficult to have and use only one single type of aircraft to provide all routes. The common reason why an airline could only order one type of aircraft is to cut its maintenance facility cost. The airlines also have a choice whether they want to have many different types of aircraft or they want to have only one type of aircraft. Having more than one type of aircrafts means that the airlines will order the aircraft to more than one manufacturers, but many types of aircrafts also defined as order the aircraft from one manufacturer but comes from different aircraft family (Zou, Yu, \& Dresner, 2012). Fleet management that is using commonality concept has to cover long terms planning, which are size, type, and choices of manufacturer, included schedule and routes. Having mistakes in selecting what aircraft that airlines should use can make the business suffered and cannot survive in this industry (Simarmata \& A.N, n.d.). The challenge in airline fleet management is to balance between the benefits of fleet commonality or uniform fleet and the choice of the aircraft that must be suitable for different routes and services.

Commonality in airline definitely will influence direct maintenance cost for the aircraft. An airline that use commonality concept will only use one type of aircraft from one single manufacturer which only has one single engine type and one common cockpit design. Cockpit is the important section which should be very desirable simply for airlines companies to train the pilots. If airlines have many different types of cockpit, they will reduce the time to train their pilots from one type of aircraft to other types of aircraft. Direct maintenance cost for airlines with commonality concept will be lower than the airlines without commonality concept. Generally, it can be seen from engine maintenance. Engine maintenance takes a big part in influencing the direct maintenance cost, because for airlines with commonality concept, the engine itself is exchangeable between the aircrafts within one family or one type and one type engineer. However, for 
the airlines without commonality concept, they have to hire more than one type engineers with different licenses to maintain the aircraft engine and stock more the engines of different aircrafts.

Maintenance activity completes by the aircraft should be scheduled. Hence, there is maintenance interval. Maintenance interval should be conducted in a certain period of time after the aircraft is already achieved its total flight hours.(Wang, Gao, \& Wu, 2014)found that the extension of maintenance interval could increase the availability of the aircraft and reduce aircraft maintenance cost.

Based on the explanation of introduction, we describe our framework of shifting aircraft from uncommon to common:

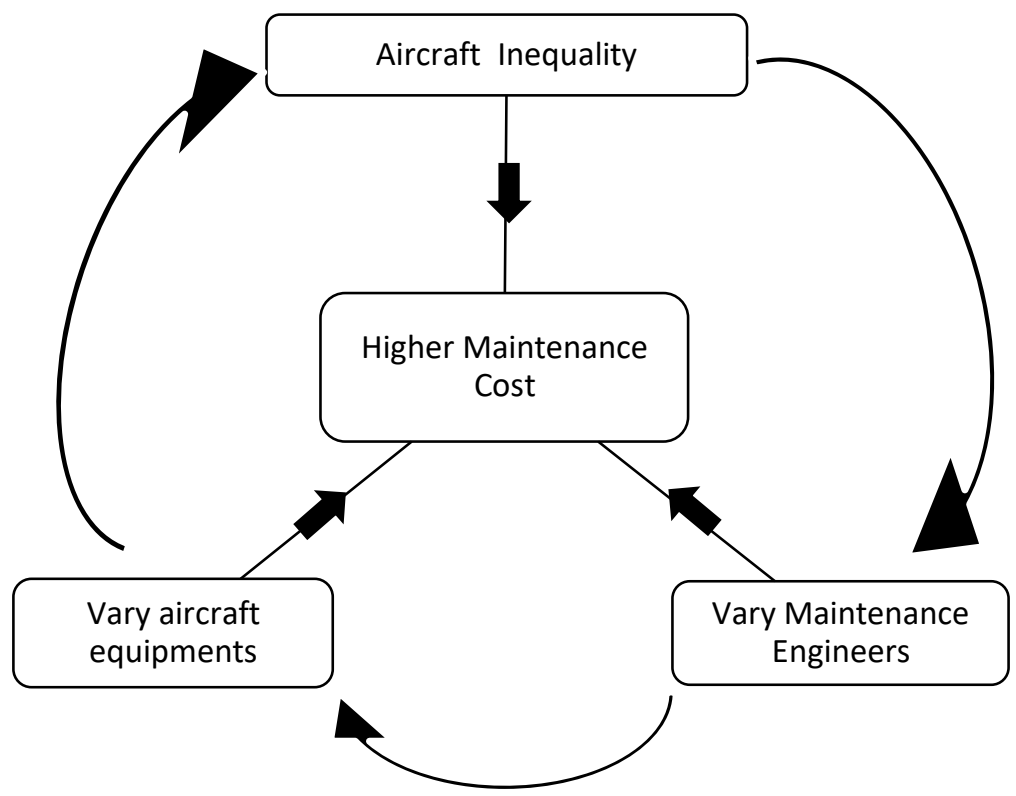

Figure 1.

The level of maintenance cost occurs due to three factors above. Basically, those three factors are related to each others. Aircraft components for maintenance should be placed by the maintenance engineer perfectly, means that the human resources factor is very needed in maintenance activity. Then for the last factors which is aircraft inequility means that whether the airlines have many types of aircraft or not. Aircraft inequality will affect the aircraft component and human resources factors. Therefore, aircraft inequality will increase maintenance cost. 


\section{Method}

Airlines total cost is highly influenced by the aircraft maintenance cost, although maintenance cost is not direct cost of the airlines but still it has high impact to control the profit and loss which can be obtained by the airlines. The data to strengthen this analysis is obtained from interviewing the airlines expert and reviewing the literature.

Aircraft maintenance typically consists of scheduled maintenance (preventive maintenance) and unscheduled maintenance (corrective maintenance). From this side, the scheduled maintenance is contributed to lower cost because the engineers are not doing any action to restore an item that has been malfunction, it is only taking retain action to keep the items in a stable condition. On the other hand, unscheduled maintenance is the opposite situation of the scheduled maintenance.

Aircraft maintenance cost also depends on the type of the aircraft. Based on to the interview, researchers find out that airlines embrace fleet commonality concept spent lower maintenance cost rather than the ones without it. Fleet commonality concept forces the airlines to only have one fleet family which means the action of maintenance for the aircraft will be the same.

The level of the maintenance cost could also be based on the type of the aircraft maintenance. $\mathrm{Wu}$ in her work entitled method to reduce direct maintenance cost for commercial aircraft said that type of maintenance for aircraft is classified into two types. The first one is called corrective maintenance also known as unscheduled maintenance. In this type of maintenance, it covers all actions of correcting and suspecting malfunction or deject failure item and restore it to get back to a normal condition. It is also including fault verification, fault isolation, disassembly, replacement, and alignment. It has a benefit which is to ease the burden on the maintenance resource. The second one is preventive maintenance or can called scheduled maintenance. It covers all actions that performed to retain an item of the aircraft to be in a stable condition and also covers systematic 
inspection, detection, replacement, adjustment, calibration and cleaning (Wu, Liu, Liu, \& Ding, 2004).

Based on the explanation above, we know that higher maintenance cost will appear if the airlines do a lot of unscheduled maintenance for the aircraft, because unscheduled maintenance can happen when the aircraft is already not in a predictable malfunction situation, which means the equipment of the aircraft is not working well anymore. With this condition, the malfunction or broken equipment can be repaired if it is possible, or it should be replaced with the new one if the damage is already severe and will spend much cost over the budget.

Irregularities handling of aircraft could also increase the level of maintenance cost. Sari in her work explains that irregularities handling caused by several factors, which are: the old age of ground support equipment, lack of briefing and debriefing of aircraft handling, and lack of work motivation and incentives (Sari, 2016).

Aircraft has a lot of important component that should be treated regularly to make sure that the aircrafts is feasible or not to fly. Therefore, the aircrafts have component or item listed in "go item" and "no go item". Once the aircrafts do not have component in "go item" such as life jacket, the aircrafts still can fly because it can be installed after the aircraft arrived at the destination. However, for "no go item", if the aircrafts have a problem in component that listed in "no go item", then the aircrafts will forbid to fly because "no go item" is the component that will affect the safety of flight.

Refer to the maintenance cost, it is related with the fluctuations of ticket price that the airlines published to its customer. Ticket price which published by the airlines to their customers related with the service given by the airlines to their customers, there are three types of airline based on its service type, which are: full services, medium services, and no-frill services (Martono, Marina, \& Wardana, 2016). The airlines which sell lower price of ticket will get more passengers to be carried by those airlines though in this condition, the airlines will get interference in maintenance cost. The lower ticket price which already being the income for the airlines cannot cover the 
maintenance cost for the aircraft in the airlines. It happens because the income gained by the airlines will spin to be used as operation cost for the airlines, while Prasadja Ricardianto et al stated air transport mode is the safety and comfortable transportation mode (Ricardianto, Djajaputra, Martono, \& Introduction, 2017). That is the reason why if the airlines sell a ticket with lower price, the passenger will question about the maintenance handling of the aircraft especially the aircraft safety and security

This table will describe in detail about the elements that involved in direct maintenance cost for the aircraft:

Table 2.

Aircraft Maintenance Check List

\begin{tabular}{|c|l|}
\hline No & \multicolumn{1}{|c|}{ Aircraft Maintenance } \\
\hline 1 & Pre Flight Check \\
\hline 2 & Transit Check \\
\hline 3 & Post Flight Check \\
\hline 4 & Line Check \\
\hline 5 & "A" Check \\
\hline 6 & "B" Check \\
\hline 7 & "C" Check Inspection \\
\hline 8 & Out of Phase Check \\
\hline 9 & Structural Maintenance Check \\
\hline 10 & Compass Swing \\
\hline 11 & C of A Inspections \\
\hline 12 & C of R \\
\hline 13 & Engine Replacement \\
\hline 14 & Propeller Replacement \\
\hline 15 & Landing Gear (L/G) Replacement \\
\hline 16 & Corrosion Protection \& Continuous program \\
\hline & \\
\hline
\end{tabular}

Based on table 2, to do the maintenance, the airlines should know the period for overhauling the aircraft. The period and aircraft maintenance scheduling should fit the time. The aircraft which will do maintenance has to make sure about the hangar list scheduling. Do not let the aircraft is doing overhaul when the hangar is full, if the hangar is full means the aircraft will 
be placed in waiting list and if this condition occurs, the aircraft will have less flight hours because of the 'waiting list' condition. Less flight hours obtained by the airlines influence the profit that can be gained by the airlines.

Therefore, the airlines should match the aircraft maintenance scheduled and aircraft operations scheduled. Both of maintenance department and operation department should collaborate with each other and also involve marketing department about the schedule arrangement for the aircraft because marketing department is the key division which contribute to find revenue for the airlines. Ideal time for doing aircraft maintenance is when the airlines faced low season. Usually in low season, the marketing scheduler will reduce flight frequency in order to let the aircraft being overhauled. But, if aircraft is forced to be in waiting list, then the airlines have to come up with other plans in order to meet the needs of passengers who will have a trip to some places using air transport mode. It means the company should prepare other aircraft to replace the operation of overhauled aircraft placed in waiting list. It takes 3 months to overhaul an aircraft. It is really easy if airlines use commonality concept. By having only one-single type of the aircraft, the chance of troubled the scheduling could be minimized.

Table 2.1

Maintenance Reserves

\begin{tabular}{|c|l|}
\hline No & \multicolumn{1}{|c|}{ Maintenance Reserves } \\
\hline 1 & Landing Gears Overhaul \\
\hline 2 & Engine Life Limited Parts \\
\hline 3 & Engine Shop Visit (Performance + Replacement) \\
\hline 4 & Air Frame \\
\hline 5 & Repair \& Overhaul Rotable Component \\
\hline
\end{tabular}

Source: (Authors) 
Table 2.2

Additional Maintenance

\begin{tabular}{|c|l|}
\hline No & \multicolumn{1}{|c|}{ Additional Maintenance } \\
\hline 1 & ATC Transponder Check \\
\hline 2 & Altimeter Check \\
\hline 3 & ELT Inspection \\
\hline 4 & VOR Check \\
\hline
\end{tabular}

Source: (Authors)

From the table above, in case airline companies do not have any their own maintenance reserve, shop maintenance or maintenance reserve can be done by the third party who has aircraft maintenance facility. Maintenance reserve takes almost $65 \%$ of direct maintenance cost. The cost for maintenance reserve should be saved first by the airlines, i.e. for every onehour, direct maintenance cost for Boeing 737-700 achieved USD 600. If maintenance reserve takes $65 \%$ from direct maintenance cost, It means the company has to save USD 390 for maintenance reserve and the rest is for additional maintenance and maintenance checklist. Maintenance reserve cost covers aircraft insurance, crucial aircraft elements purchase such as engine, landing gear, aircraft power unit, etc.

The direct maintenance cost is the total of maintenance checklist, maintenance reserve, and additional maintenance that should be spent by the airlines. In maintenance reserve, we mentioned about rotable component and it is clearly explained also that the third party could done maintenance reserve. Then, for doing repair and overhaul rotable component, the component can be stocked by the airlines itself or the third party.

Airlines choose to prepare the component by itself in order to reduce the cost, because the price of the component provided by third party is usually more expensive than the actual price. Airlines with commonality concept will not have many stocks for the component of the aircraft, 
because if the component is rotable, it can be exchanged to other aircraft within one type.

The landing gear overhaul for the aircraft is usually done after the aircraft is already achieved 18000 flight hours. To undertake landing gear overhaul it will take around 30 days-60 days related with the type of the aircraft. The size of landing gear overhaul cost depends on the complexity of the gear.

Landing gear overhaul can be done in two programs, which are with loan program and exchange program. By doing loan program, airlines can lease spare gear for the aircraft when its original gear is being overhauled, after overhauling process is done, those original gear can be reinstalled to the aircraft again. For exchange program, when the original gear is being overhauled, the overhaul specialist will give another designated spare gear for the aircraft. Spare gear provided by the overhaul specialist will be an exchange unit for the aircraft. Indirectly, the aircraft will have two gears that can be used for another aircraft within the same type. With exchange program, airlines will cost more at the beginning, but as time goes by airlines will minimize the cost because airlines do not have to lease any gear again (Ackert, 2012).

\section{Discussion and Result}

Fleet commonality concept evidently is one of the solutions to reduce the cost that must be spent by both airlines and maintenance facilitator. Based on the analysis above, the advantage of fleet commonality concept is not only reducing the cost, but also helping the airlines easier to schedule of the aircraft operations. The aircraft schedule is easier to be made without having cancellation because there is a prepared one type aircraft if it happened to be another aircraft is overhauled. Besides many advantages that can be obtained by embracing fleet commonality concept, there will also be shortcomings in implementing fleet commonality concept. Authors find out the airlines will get operation loss if all aircrafts with the same type is being grounded. Grounded or Aircraft on Ground is indicating the aircraft has a 
serious problem resulting in the prohibited aircraft to fly. This is related to fleet commonality concept, once the airlines embrace fleet commonality concept and the similar case above happen, it will make the airline loss in revenue. If at first the airlines could operate 150 aircraft with 75 Boeing 737-700 aircraft and 75 Airbus A380 aircraft, then Airbus A380 is getting grounded, the airlines can only operate Boeing 737-700 as many as 75 aircrafts and it cannot cover the airlines revenue compare with using Airbus A380. Aircraft on Ground will impact the fluctuations of revenue and also cost for the airline itself.

\section{Conclusion}

As the growth of airlines' industries in recent years, many airlines compete to gain more profit with affordable cost that must spent by the airlines. Basically, every airline has the choice to choose what type of aircraft that they want to use. However, the airlines do not only serve one type of routes, this condition forces the airlines to various types of aircraft. The existing of commonality helps the airlines to lower their operational cost, mostly operational cost will be reduced in the maintenance cost and also crew cost.

There are advantages and disadvantages when the airlines embrace fleet commonality concept. The benefit is by using only one type of aircraft family, it will make the airlines more efficient. Refer to commonality; the party which involved undertaking fleet commonality concept is not only the airlines, but also involving other parties such as MRO, manufacturer, ground handler, etc.

In this research, authors still have a lot of limitations for doing further research because authors only did the observation through literature study and interview only several airline experts. Hopefully, in the future research, the authors will be better in conducting the field study to the related companies for collecting data. 


\section{References}

Ackert, S. (2012). Basics of Aircraft Maintenance Reserve Development and Management.

Brüggen, A., \& Klose, L. (2010). How Fleet Commonality Influences LowCost Airline Operating Performance : Empirical Evidence. Journal of Air Transport Management, 16(6), 299-303.

Heisey, R. (2002). Low Maintenance Cost and High Dispatch Reliability. Aero Magazine No. 19 717-200, (19).

IATA. (2011). Airline Maintenance Cost Executive Commentary.

ICAO. (2017). Airline Operating Costs and Productivity, (February).

Jani Kilpi. (2007). Fleet composition of commercial jet aircraft 1952 2005 : Developments in uniformity and scale, 13, 81-89.

Martono, K., Marina, S., \& Wardana, A. (2016). Domestic Air Transport Regulations in Indonesia. Jurnal Manajemen Transportasi Dan Logistik, 3(1), 1-19.

Ricardianto, I. P., Djajaputra, G., Martono, P., \& Introduction, I. (2017). Air Transport and Tourism in Indonesia. IOSR Journal of Applied Chemistry, 10(5), 1-19.

Sari, M. (2016). Factors Causing The Irregularities of Airplane Medical Evacuation Handling in Halim Perdana Kusuma Airport. Jurnal Manajemen Transportasi Dan Logistik, 3(3), 309-316.

Simarmata, J., \& A.N, C. (n.d.). Analysis and Evaluation on the Strategy of Indonesian Airline Companies to Face the Increasing Price of Avtur and the Decreasing Exchange Value of Rupiah against the US Dollar, (2), 1-16.

Simarmata, J., Suryana, Y., Kaltum, U., \& Oesman, Y. M. (2016). Airline Customer Retention in Indonesia 2015. International Journal of Management Science and Business Research, 5(2), 41-53.

Wang, H., Gao, J., \& Wu, H. (2014). Direct Maintenance Cost Prediction of Civil Aircraft. Aircraft Engineering and Aerospace Technology: An International Journal, 86(5), 406-414.

Wu, H., Liu, J., Liu, Y., \& Ding, Y. (2004). Method to Reduce Direct Maintenance Cost for Commercial Aircraft. Aircraft Engineering and Aerospace Technology: An International Journal, 76(1), 15-18.

Zou, L., Yu, C., \& Dresner, M. (2012). Fleet Standardization and Airline Performance, 1-29. 